\title{
Spectrum of Congenital Heart Disease at Sheri-Kashmir Institute of Medical Sciences
}

\author{
Gousia Mukhtar ${ }^{1}$ Aamir Rashid ${ }^{2}$, Hilal Rather, ${ }^{3}$ Bashir Charoo, ${ }^{4}$ Syed Wajid Ali, ${ }^{5}$ \\ Nisar Trambo, 'Imran Hafeez ${ }^{7}$
}

1.4.5 Department of Paediatrics, SKIMS

2.3.6.7 Department of Cardiology, SKIMS

\section{A B S T R A C T}

\begin{abstract}
Background: Congenital Heart disease accounts for $10 \%$ of infant deaths in developed countries. Very scarce data exits about the prevalence and patterns of $\mathrm{CHD}$ in our local high altitude population

Aims: To analyse the pattern and burden of congenital heart disease at a tertiary care cardiac centre in a high altitude region of Northern India. Material and Methods: A retrospective study was conducted in the Department of Cardiology and Department of Paediatrics of our institute which is the only major referral centre of the region. Case records of 125142 patients (Age 0-16yrs) attending the hospital from November, 2013 to August, 2017 were analysed

Results: 1596 out of the total of 125142 patients were found to have CHD giving a prevalence of 12.7 per 1000 attending patients. About 1247 had acyanotic CHD (78.2\%) of which most common was VSD (33\%) followed by PDA (21.7\%). Cyanotic heart diseases represented $21.8 \%(349$ cases) of which TOF was most common ( $44 \%)$ followed by TGA $(15 \%)$. Only three cases of a total of 53 cases of TGA were TGA IVS.DORV ( $8.8 \%)$ was third most common followed by Single ventricle(8.3\%). Only 3 of a total of 349 cases of CCHD were HLHS.

Conclusion: A prevalence of 12.7 per 1000 attending patients is fairly high. Our study noted that the spectrum of CHD was mostly similar to the published literature. In addition, it draws attention to the almost negligible detection of critical congenital heart disease in the neonatal period.

Key words: Congenital Heart disease, high altitude, prevalence, Pattern

JMS: 2019; 22(3):12-15 DOl: https://doi.org/10.33883/jms.v22i3.451
\end{abstract}

\section{INTRODUCTION}

Congenital Heart Disease has been defined as a gross structural anomaly of the heart or intrathoracic great vessels that is actually or potentially of functional significance. ${ }^{[1]} \mathrm{CHD}$ is considered to be the most common congenital malformation which still accounts for $10 \%$ of infant deaths and nearly half of all deaths from congenital malformations in developed countries. ${ }^{[2,3]}$ Situation in India is likely to be worse due to high birth rate. ${ }^{[4]}$ Approximately 2,00,000 children are born with CHD each year with one third to one half requiring early intervention ${ }^{[5]}$ of which only $3 \%-5 \%$ receive timely surgery. ${ }^{[6]}$

\section{Access this article online}

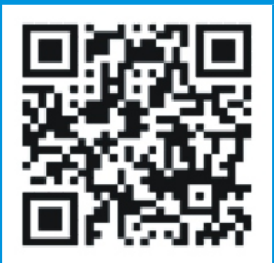

Website:

www.jmsskims.org

DOI:

https://doi.org/10.33883/jms.v22i3.451
Given the huge impact congenital heart diseases make on infant health, it should be a priority for research and that was the motivation behind conduct of this study. The major purpose of doing a prevalence study on CHD is to raise awareness not only of the major congenital heart defects that are frequently diagnosed after a considerable delay but also of the rare defects that are usually underdiagnosed. Prevalence studies have been carried out in the past from the

Correspondence:

Dr. Aamir Rashid,D.M

Assistant Professor, Department of Cariology, SKIMS

Email: aamirrashid11@yahoo.co.in

How to cite this article: Mukhtar G, Rashid A, Rather $\mathrm{H}$, Charoo B, Ali S, Tramboo N, Hafiz I. Spectrum of congenital heart disease at Sheri-Kashmir Institute of Medical Sciences. jms 2019;22(3):12-15

Received: 13-05-2019 Accepted: 03-07-2019 


\section{Mukhtar G et al; Spectrum of Congenital Heart Disease at Sheri-Kashmir Institute of Medical Sciences}

region ${ }^{[7]}$ but this is the first such study from the sole tertiary care cardiac centre of the region catering a population of over 70 lacs. This study aims at analyzing the pattern and prevalence of CHD in a territory care centerof high altitude valley of Northern India and thus is expected to answer whether high altitude has a significant effect on the spectrum of CHD.We also aimed at knowing the spectrum of CHD in the genetic syndromes that we encountered and to highlight the importance of diagnosing certain rare diseases that are not usually suspected and thus, often missed.

\section{MATERIAL AND METHODS:}

This retrospective observational study was conducted in the Department of Cardiology and Department of Pediatrics of our institute which is the only major referral cardiac centre of the region. Case records data of 125142 patients (Age 016yrs) attending the Paediatric OPD from November, 2013 to August, 2017 were analysed.

Patients were suspected of CHD if they complained of Breathlessness on feeding, excessive sweating, failure to thrive, cyanosis, had abnormal heart sounds or cardiac murmur on examination. Patients were evaluated by chest xray, ECG and echocardiography. ECHO was done by the pediatric cardiologist of the institute according to the recommendations of the American Society of echocardiography. Spectrum of CHD was then analysed along with gender distribution and age of presentation. Statistical package SPSS version 20.0 (SPSS Inc., Chicago, Illinosis, USA) was used to carry out statistical analysis of data. Prevalence rate per 1000 population and relative frequency of individual CHD s as proportion of total CHD s was calculated. All cases were followed up after surgical or medical management in the pediatric cardiology clinic.

\section{RESULTS}

During the study period of about three years and ten months, 125142 patients attended the pediatric OPD. 1596 patients were diagnosed with CHD with calculated prevalence of $12.7 / 1000$ attending.Of the 1596 CHD patients, 850 were male (53.2\%) and $736(46.1 \%)$ were female. Only 55 patients were diagnosed less than 1 month age of which only 12 were critical CHDs. $38 \%$ of CHD s reported to us in 1-12 months age group, the period when most CHD s present. This was followed by the 5-16 yr age group during which $33 \%$ patients have presented. $24 \%$ patients presented in the 1-5 yr age group.

About 1247 had acyanotic CHD (78\%) of which most common was VSD (33\%) followed by PDA( 21.7\%), $\operatorname{ASD}(14.7 \%), \mathrm{PS}(7.2 \%), \mathrm{AS}(5.9 \%), \mathrm{AV}$ canal defect (4.5\%), MVP /MR (1.9\%) and coarctation of aorta (1.5\%).Spectrum of acyanotic CHD as per age of presentation and gender is given in table 1.The frequency of subtypes of major CHD s are also given in the table and the distribution of various subgroups of VSD s are separately given in Table 2.

Cyanotic heart diseases represented $21.8 \%$ of which TOF was most common (44\%) followed by TGA (15\%),DORV (8.8\%), SV physiology (8.3\%), Ebstein anomaly (5.1\%) and Tricuspid atresia (4.8\%).Spectrum of cyanotic CHD as per age of presentation and gender is given in table 3.Spectrum of CHDs in different syndromes is given in table 4

\section{DISCUSSION}

We found a CHD prevalence of 12.7/1000attending patients which is fairly high. Studies from India have reported a huge variation in prevalence from as low as 1.3/1000 to as high as 26.8/1000 population ${ }^{[8,9]}$ The high prevalence found in our study may reflect the effect of high altitude on prevalence of CHD. Studies reporting high prevalence were similarly conducted in high altitude areas ${ }^{[10]}$. Our study may have overestimated true prevalence of CHD as ours is a tertiary care cardiac centre where all patients from the region are ultimately referred to. Studies reporting a low prevalence from the region ${ }^{[]]}$were conducted in pediatric departments which are not cardiac referral centres and thus may have underestimated true prevalence of CHD.

VSD was the most common acyanotic lesion followed by PDA. ASD was the third most common CHD.Other studies conducted by researchers at high altitude ${ }^{[1,1,13]}$ similarly found a high prevalence of PDA and ASD. It is postulated to be as a result of lower atmospheric oxygen tension present at high altitude which fails to constrict the ductus. It is theorized that persistence of high PVR and high right heart pressures inhibit early closure of PFO. Subsequent growth may result in stretching of fossa ovalis and incompetence of the flap which produces an ASD.$^{[14]}$ Two of our patients had a combination of valvular aortic and pulmonary stenosis which is a rare lesion. Deletion of a chemokine receptor CXCR7 found in cushion mesenchymal cells in the 


\section{Mukhtar G et al; Spectrum of Congenital Heart Disease at Sheri-Kashmir Institute of Medical Sciences}

developing heart, result in both aortic and pulmonary stenosis. ${ }^{[15]}$ Posing significant challenges in diagnosis and management, much needs to be studied about the clinical and hemodynamic findings of the entity.

As with other studies ${ }^{[16]}$, TOF was the most common cyanotic CHD.About the age distribution of TOF, it was striking that a significant proportion of patients ( 56 of 154 ; $36.3 \%)$ presented at $5-15$ yrs age group. This delayed diagnosis of TOF brings forth the point that TOF patients might be more likely to be missed in early stages of life as they do not have recurrent severe pneumonias and are thus less likely to be referred to a tertiary care centre. This is contrary to the study by Rashid et a $\mathrm{l}^{[17]}$ who found that acyanotic patients are more likely to be diagnosed late. In our study, we also found delayed presentation for acyanotic CHD s for instance, VSD. 151 of 414 VSD patients (36\%) presented in 5-15 yr age group but that is mainly for small restrictive VSD swho do not have severe pneumonias and for which delayed referral does not make a very big difference. In our study, only 15 of 107 (12\%) large VSD s presented in the 5-15 year age group. We are well aware of the fact that delayed surgical repair of TOF is associated with high surgical risk. This highlights the importance of educating primary care physicians, school teachers and other health workers about the presentation of cyanotic heart diseases and the importance of early referral.

The second most common cyanotic CHD was TGA. Only a shocking 3 out of 53 cases of TGA are TGA IVS.This indicates that TGA IVS might be frequently missed and die without being referred to a tertiary care centre as this disease has a stormy course in absence of treatment and moreover, facilities for diagnosing such sick patients are usually not available in many NICU s of the region.DORV was the third most common CCHD ,Single ventricle the fourth most common and Ebstein anomaly the fifth most common CCHD. We have found a higher prevalence of Ebstein anomaly than rest of the studies which may reflect effect of high altitude on spectrum of CHD. ${ }^{[18]}$ Also, HLHS was almost non existent. Only 3 out of 349 cases were diagnosed, again emphasizing the fact that critical CHD s which must be diagnosed in the first few days of life often go unrecognized.

A total of 177 out of 1596 patients (11\%) had other associated genetic anomalies out of which Down s syndrome was the most common. Complete AV canal defect was the most common defect found in Down syndrome patients.

Other than the major anomalies, certain rare but clinically important and frequently missed CHD s like Vascular ring, Abernethy malformation and Tricuspid valve dysplasia were found in one, two and one case respectively. Patients of vascular ring have recurrent pneumonias, stridor, reflex apneas with eating and chocking on feeds. Since these symptoms occur in a variety of pediatric diseases, vascular rings are frequently missed if a high index of suspicion is not maintained. We report two cases of Abernethy malformation both of whom had recurrent chest infections, cyanosis and clubbing and had remained undiagnosed till adolescence. Clinicians should always be aware of the possibility of such rare diseases. Dysplastic tricuspid valve is often confused with PPHN in neonates if the clinician does not carefully look for secondary causes of TR and PAH in the newborn.

The main limitation of our study was that it was a hospital based study conducted in a tertiary referral centre of the region. So, it might have overestimated the prevalence of $\mathrm{CHD}$ in the region.Screening of new-borns must be done at birth. Such a study would bring forth actual prevalence of CHD and especially critical CHDs in the region.Further research must be undertaken to know the antenatal risk factors and genetic abnormalities that play role in causation of congenital heart disease.

\section{DECLARATIONS}

Conflict of interest: NIL

Funding Sources: NIL

Written informed consent: Yes

\section{REFERENCES}

1. Mitchell SC, Korones SB, Berendes HW.Congenital heart disease in 56,109 births.Incidence and natural history. Circulation. 1971; 25:323-32

2. Wren C, Reinhardt Z, Khawaja K. Twenty-year trends in diagnosis of life-threatening neonatal cardiovascular malformations. Arch Dis Child Fetal Neonatal Ed 2008;93:F33-5.

3. Dolk H, Loane M, Garne E; for the European 
Mukhtar G et al; Spectrum of Congenital Heart Disease at Sheri-Kashmir Institute of Medical Sciences

Surveillance of Congenital Anomalies (EUROCAT) Working Group. Congenital heart diseases in Europe: Prevalence and perinatal mortality, 2000 to 2005. Circulation 2011; 123:841-9

4. Saxena A, Mehta A, Sharma M, Salhan S, Kalaivani M,RamakrishnanS, et al. Birth prevalence of congenital heart disease: A cross-sectional observational study from North India. Ann Pediatr Card 2016; 9:205-9.

5. Saxena A. Congenital heart disease in India: A status report. Indian J Pediatr 2018; 55:1075-82

6. Kumar R K;Congenital Heart disease ;Parthasarathy A, Menon PSN editors ; IAP Textbook of Paediatrics. $5^{\text {th }}$ ed;pp 427

7. Wanni KA, Shahzad N, Ashraf M, Ahmed K, Jan M, Rasool S. Prevalence and spectrum of congenital heart diseases in children. Heart India. 2014:2;3;76-9

8. Kapoor R ,Gupta S. G Prevalence of congenital heart disease in Kanpur, India, Indian Pediatrics. 2008; 45: 309-311

9. Smita R, Karat SC, Narayanappa D, Krishnamurthy B, Prasantgh SN, Ramachandra NB. Prevalence of congenital heart disease in Mysore.Indian J Hum Genet 2006; 12:11-16

10. Bhat NK, Dhar M, Kumar R, Patel A, Rawat A, Kalra BP. Prevalence and pattern of congenital heart disease in Uttarakhand, India. Ind J Pediatr. 2013;80(4):281-5.

11. SandridgeAL, Greer W, Al-Menieir M, Rowais AA. Exploring the impact of altitude on congenital heart defects in Saudi Arabia. Avicenna. 2010 Feb 10;2010(1):3.
12. Miao CY, Li WX, Geng D, Tao LA, Zuberbuhler JS, Zuberbuhler JR. Effect of high altitude on prevalence of congenital heart disease. Chin Med J. 1988 Jun; 101(6):4158.

13. Miao CY, Zuberbuhler JS, Zuberbuhler JR. Prevalence of congenital cardiac anomalies at high altitude. J Am CollCardiol. 1988 Jul;12(1):2248.

14. Bhardwaj R, Kandoria A, Marwah R, Vaidya P, Singh B, Dhiman P, et al. Prevalence of congenital heart disease in rural population of Himachal - A populationbased study. Indian Heart J. 2016 Feb;68(1):4851.

15. Yu S, Crawford D, Tsuchihashi T, Behrens TW, Srivastava D. The chemokine receptor CXCR7 functions to regulate cardiac valve remodeling. Dev Dyn. 2011 Feb;240(2):38493.

16. Vyas PM, OswalNK, Patel IV. Burden of Congenital Heart Disease in a Teritiary Cardiac care Institute In western India: Need for a national Registry. Heart India 2018;6:45-50

17. Rashid U, Qureshi AU, Hyder SN, Sadiq M. Pattern of congenital heart disease in a developing country tertiary care center: Factors associated with delayed diagnosis. Ann Pediatr Card 2016; 9:210-5

18. Abqari S, Gupta A, Shahab T, Rabbani M U, Ali S M, Firdaus U. Profile and risk factors for congenital heart defects: A study in a tertiary care hospital. Ann Pediatr Card 2016; 9:216-21 